DOI: $10.15593 / 2224-9354 / 2019.4 .13$

УДК 316.334:614.2

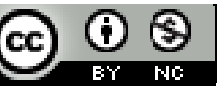

\title{
P.T. Насибуллин
}

\section{ЗДРАВООХРАНЕНИЕ КАК СОЦИАЛЬНЫЙ ИНСТИТУТ}

\begin{abstract}
Каждый из нас в течение всей жизни, вслед за родителями, друзьями, коллегами, следуя их примеру, сталкиваясь с проблемами здоровья, обращается к докторам или к народной медицине. Так у каждого человека, в том числе и у исследователей, складывается представление о том, что такое здравоохранение: одни рассматривают его как отрасль народного хозяйства, другие - как систему государственных органов, занимающихся организацией оказания медицинских услуг населению и т.д. Автор статьи характеризует здравоохранение как социальный институт. С этой точки зрения контрпродуктивно рассматривать здравоохранение в качестве отрасли народного хозяйства, как с позиции науки, так и практической целесообразности. Полноценная реализация национального проекта «Здоровье» возможна только при условии, когда такие изобретения, соединяющие силы природы и человеческого духа, как Газпром, Роснефть и др., начнут работать на систему здравоохранения страны в качестве полноправных участников совместной деятельности, основная цель которой не превращение сущностных сил населения в деньги ценой его здоровья, а создание таких условий и такого качества жизни людям, чтобы каждый ребенок мог бы получить достойное образование, качественную профессиональную подготовку, затем и достойную форму развития и проявления своих способностей, фрормировать отношение к своему физическому и духовному здоровью как к высшей ценности. нормы.

Ключевые слова: здравоохранение, социальный институт, функции, дисфуункции, роли,
\end{abstract}

В специальной литературе, посвященной проблемам развития системы здравоохранения, она называется по-разному: и «сферой» [1, с. 158], в которой Министерство здравоохранения проводит государственную политику, и «комплексным институтом» [2, с. 219], и «...системой, направленной на создание и укрепление здоровья нации...» [3, с. 11], и институтом здравоохранения [4], и как элемент социальной системы [5], могут и в одной статье назвать «...одним из звеньев социальной сферы», «отраслью социальной сферы» [6, с. 162] и т.д. Казалось бы, не так трагичны аспекты значения этих слов, однако в совокупности такие разночтения способны породить определенные проблемы по мере роста числа и частоты их применения.

Но, во-первых, в социологии есть система категорий, которые воспринимаются как научные, которые используются большинством исследователей в теоретических и в эмпирических исследованиях: социальный институт, социальная организация, социальная группа и т.д.

Во-вторых, имеются сущностные особенности того, что мы называем отраслью народного хозяйства, учреждением, сферой общества.

() Насибуллин Р.Т., 2019

Насибуллин Равиль Талибович - д-р социол. наук, профессор, завкафедрой социологии и социальных технологий ФГБОУ ВО «Уфимский государственный авиационный технический университет», e-mail: nasibullin@inbox.ru. 
В-третьих, социальные институты не создаются, как считают некоторые авторы [7], а возникают, являются результатом совместной деятельности людей, направленной на удовлетворение жизненных потребностей индивидов, как стандартизированная модель поведения [8]. В отличие от учреждений и отраслей, в которых человек проводит только часть своей жизни, в социальных институтах, в частности, в системе здравоохранения, проходит вся наша жизнь. Для примера: в нефтяной отрасли, в ее организациях человек имеет ценность исключительно как источник рабочей силы от 18 до 65 лет, если доживет; а в системе здравоохранения он находится от рождения до самого конца жизни и не как источник рабочей силы, а именно как самоценность.

В-четвертых, здравоохранение как социальный институт имеет сложную внутреннюю структуру как совокупность медицинских учреждений и организаций, функционирование которых обеспечивается государством в форме общегосударственной, муниципальной и частной систем охраны здоровья людей. Параллельно, в системе здравоохранения существует еще и народная медицина, основанная на утвердившихся в народном опыте методах оздоровления, как это определено в Федеральном законе «Об основах охраны здоровья граждан в Российской Федерации». В самом деле, несправедливо было бы думать, что до описываемых нами времен у каких бы то ни было народов не было своей системы здравоохранения и культуры исцеления от различных ранений и болезней. Нельзя отрицать и то, что сегодня значительная часть граждан пользуется услугами народных целителей.

В-пятых, здравоохранение выполняет присущий только ему ряд функций, имеющий свою специфику:

- регулирует отношения между людьми через выработку определенных привычек, моделей поведения в отношении обеспечения желаемого индивидуального и общественного состояния здоровья;

- обеспечивает активное предметное взаимодействие людей, социальных групп общества вокруг проблем сохранения и улучшения здоровья;

- интегрирует индивидов вокруг задач, решаемых медицинскими учреждениями;

- осуществляет накопление и передачи знаний, формирование навыков, необходимых для обеспечения нормального функционирования организма человека;

- формирует общественное мнение о здоровье человека на основе научных знаний и медицинской практики.

Говоря о функциях здравоохранения как социального института, имеем в виду также давно установленные наукой и подтвержденные практикой функционирования социальных институтов такие явления, как дисфункция, явные и латентные функции, сущность которых раскрыта в учебниках [9]. Так же, как и другие социальные институты, здравоохранение как социаль- 
ный институт, характеризуется не только выполнением определенных функций, но и дисфункциями, например, функция оказания медицинских услуг пациенту может быть подменена зарабатыванием денег путем установления тарифов за дополнительные услуги и т.д.

Другое дело, когда говорят о латентных функциях социальных институтов [10]. Применительно к здравоохранению, как к социальному институту, речь идет о том, что в процессе лечения пациента на основе вполне верно поставленного, обоснованного диагноза может получиться рецидив усложнения состояния другого органа пациента, не говоря уже об ошибочном диагнозе и выбранного на основе этой стратегии и тактики лечения. Латентная функция проявляется, например, в процессе подготовки медицинских работников в специализированных учебных заведениях. В самых лучших побуждениях, мы собираем группы обучающихся в одну аудиторию, в течение 90 минут один и тот же преподаватель читает для всех одну и ту же лекцию. Если даже очень квалифицированный лектор, он читает свою лекцию для всех, кто сидит в аудитории, независимо от того, что кто-то способен ухватить материал преподавателя сходу; для кого-то содержание лекции «дойдет» только после того, как он прочтет внимательно то, что успел записать; а кто-то не поймет и после повторного прочтения. Иными словами, в аудитории находятся слушатели с разным уровнем интеллектуального развития, преподаватель же, добросовестно выполняя свои обязанности так, как он привык это делать, он даже в скорости чтения лекции ориентируется на среднего студента. Ему некогда думать о том, что таким образом происходит нивелирование общественного интеллекта в процессе массовой подготовки будущих медицинских работников: вроде бы выполняем явную функцию - даем образование людям, а получается такой скрытый результат - «подтягиваем» интеллектуально развитых к уровню студентов среднего уровня. Это легче, чем поднимать интеллект студента среднего уровня.

В общем виде здравоохранение так же, как и другие социальные институты, функционирует в рамках существующих в обществе норм и правил, в данном случае это прежде всего Конституция страны, правовые нормы, законные и подзаконные акты, выполняя кроме специфических и общие для всех институтов функции [11]. Разумеется, в действиях и поступках отдельного индивида продолжают сохраняться и те привычки, которые обрели обыденный характер. Смысл сказанного в том, как бы ни были совершенны законы и подзаконные акты, с какой бы скоростью не увеличивалось их количество, реальная жизнь сложнее и богаче настолько, что никакая даже самая развитая система правовых норм не способна охватить все проявления множественности особенности отступлений человеческих поступков от этих норм. Особенно в тех случаях, когда принимаемые законодателем или медициной нормы не в полной мере оценивают исторический опыт, возможности 
человеческой изобретательности, или варианты действий и поступков, иногда и необъяснимых не только с точки зрения здравого смысла, но и элементарных оснований жизни.

Объективная необходимость регулирования отношений между пациентами, между пациентами и работниками медицинского учреждения, между самими работниками медицинского учреждения формирует определенные правила, разрабатываемые на основе опыта организации совместной жизнедеятельности на этой точке социального и географического пространства, которые направлены на то, чтобы определить грани и границы этих отношений.

Таким образом, функционирование социальных институтов обеспечивается системой учреждений, организаций и средствами. Особое место здесь занимает проблема статусов и ролей, выполняемых каждым человеком в рамках учреждений и организаций социальных институтов и за их пределами. В социальной системе «...минимальной единицей является роль участвующего индивидуального деятеля..., а минимальное отношение представляет собой стандартизированное взаимодействие, когда каждый участник взаимодействует как деятель, в той или иной мере ориентируясь на других...» [12].

Применительно к здравоохранению не менее сложной с точки зрения социальных отношений представляется система норм и санкций, ролей и статусов. Именно здесь складывается ситуация, когда «человек общественный» превращается в «человека индивидуального», вынужденного в силу болезни резко изменить свой социальный статус: как рабочая сила он становится не нужен работодателю; как член семьи он не только перестает быть источником дохода, но и наоборот, превращается в дополнительную нагрузку для семейного бюджета; как гражданин он перестает интересовать социальнополитические институты, он обречен оставаться один на один со своей болезнью. В лучшем случае он в определенном смысле интересен владельцу предприятия фармакологии как постоянный потребитель соответствующей продукции. В то же время он становится клиентом, получающим специфические услуги здравоохранения. Мало кому интересный как индивид, он становится объектом и центром профессионального интереса огромного количества специалистов. Но именно в качестве объекта и именно в рамках норм и правил, действующих в отрасли: один раз в день его осмотрит работник одной квалификации и назначит какие-то лекарства и процедуры, несколько раз он пообщается с работниками других категорий и квалификаций; за ним как за пациентом, будет определена какая-то точка в социальном пространстве, если это все представлять в рамках теории социального пространства.

В системе отношений между носителями социального существовал «субъект здоровый», став больным, он попадает в систему отношений между «физически и социально больным» и «профессионально здоровым». Условие легитимизации статуса больного ставит его в специфические отношения 
с людьми, которые сами больными не являются, - с членами его семьи, с врачами и т.д. [13]. Какую бы профессионально-квалификационную ценность он не представлял для общества до сих пор, теперь его профессионализм девальвируется, что приводит к ситуации, когда его социальная ценность, как члена общества, катится вниз по наклонной.

Самого крупного «в миру» чиновника или академика, министра или маршала, выдающегося писателя или композитора, рабочего или крестьянина медицинскими процедурами обеспечивать будет самый «обыкновенный» медперсонал соответствующего медицинского учреждения; убираться в помещении будет самая обыкновенная уборщица; кормить будет самая обычная «кухарка»; функционирование здания как лечебницы будут обеспечивать самые обычные рабочие-сантехники, находящиеся, в отличие от «социально значимых» пациентов, при хорошем состоянии здоровья. Представители всех этих профессиональных групп, выполняющие свои обязанности в одной целостной системе, тоже будут на глазах пациентов отождествлять медицину. Причем доктор, каким бы высококвалифицированным он ни был, отдельно от помощников меньшей квалификации, опосредованно или непосредственно занятых в процессе лечения больного, и без помощи самого больного не может оказать медицинские услуги на уровне своей квалификации. Французские социологи давно пришли к выводу о том, что отношения между доктором и пациентом способны перерасти в конфликт, связанный с расхождением их интересов и точек зрения [14].

Отсюда объективная необходимость в создании системы социального управления, которая могла бы обеспечить организацию всей совокупности медицинских услуг таким образом, чтобы пациенты разного пола и возраста, из разных социально-профессиональных и социально-квалификационных групп населения, с разным состоянием здоровья, которые для медицинского сообщества выступают как единая клиентская группа, с одной стороны, и работников медицинских учреждений, с другой, объединили свои усилия и направили на борьбу за здоровье всех и каждого.

Выше уже говорилось о том, что социальные институты возникают в результате взаимодействия людей, удовлетворяющих свои потребности путем преобразования природы. Но поскольку люди находятся в постоянном движении, система потребностей у них тоже меняется и социальные институты оказываются в условиях, когда должны быть способны удовлетворять постоянно меняющиеся потребности людей. Таким образом получается, что люди, с одной стороны, своей активной деятельностью способствуют появлению социальных институтов, будь это образование, наука или здравоохранение.

Таким образом, человек, в результате деятельности которого возникают социальные институты, и становится источником силы, вызывающей перманентные изменения в институтах, замены одних элементов системы 
другими. При этом каждый человек на своем уровне индивидуального воспринимает как данность существующие нормы, ценности, организационные формы, сложившиеся в конкретном социально-экономическом типе системы здравоохранения. Тогда как на деле он, еще не родившись, начинает активно воздействовать на существующие в обществе порядки, в том числе и в лечебно-профилактических организациях.

Бесконечное множество подобных изменений на микро- и макроуровнях и формирует вполне определенное «давление» на институт здравоохранения. Это не говорит о том, что другие социальные институты живут и функционируют по-другому. Они тоже живут под давлением всевозможных индивидуальных и групповых процессов и явлений. И проблема, как думается, не только в этом. Важнейшая задача - прогнозировать и своевременно обнаруживать противоречия, которые способны привести к аномии, чтобы обеспечить гармоничное взаимодействие социальных институтов в пределах существующих социальных норм и правил в интересах человека и общества. В данном конкретном случае, например, обеспечить подобное взаимодействие социальных институтов семьи, здравоохранения и государства, поскольку «объект» один: в семье формируются потребности человека, в том числе и в здоровом образе жизни; складывается соответствующая психологическая конституция «злого» или «доброго» человека. А к лучшему здоровью, как заметил П.А. Сорокин, имеет тенденции добрый и приветливый человек, чем недобрый и одержимый ненавистью [15].

Структура социальных институтов объективно не успевает измениться в соответствии с изменениями в системе потребностей. Потребности оказываются более мобильными по сравнению с самими социальными институтами, которые складываются в процессе их удовлетворения. В результате этого в обществе постоянно ощущается несоответствие между системой потребности людей и возможностями их удовлетворения в системе социальных институтов; кризисы происходят постоянно, представляя естественное состояние института [16]. С одной стороны, появляются новые потребности и в общественном сознании все в большей степени складывается понимание принятия определенных мер по их удовлетворению, в зачаточном состоянии отношения между людьми в процессе их удовлетворения на уровне единичного начинают складываться, а соответствующие институты еще не сложились: например, появляется в обществе новый, так называемый «средний класс», появляется потребность в соответствующих политических институтах, выражающих интересы этого класса, однако их еще нет. С другой стороны, определенные потребности удовлетворены, удовлетворенные потребности рождают новые потребности, а институты или система институтов не успевает соответствующим образом реагировать, она остается неизменной. 
Как известно, система социальных институтов нашего общества претерпевает сегодня процесс преодоления кризиса путем обеспечения перехода в новое качественное состояние: происходит двуединый процесс разрушения прежней системы институтов и возникновения новой. Иногда это называется модернизацией, которые не всегда дают желаемый результат [17], иногда они завершаются бурными революционными событиями [18, с. 120]. Причем ведущей тенденцией до сих пор остается именно крушение. Что же касается второй стороны - возникновения новых социальных институтов, то здесь в полной мере наблюдается уникальность настоящего момента: условия еще не созрели, а интерес в общественном сознании, осознание нужды в них уже существует. С другой стороны, происходит качественное изменение системы интересов и потребностей социальных групп и в обществе в целом. В этих условиях доминирующее значение будут иметь противоречия, связанные с появлением новых социальных групп со специфическими интересами и потребностями. Вокруг этих потребностей и возможных путей их удовлетворения будут складываться и уже складываются связи и отношения людей, которые постоянно будут соответствующим образом институционализироваться. Ясно, что именно вокруг этих институтов будет складываться новая система противоречий: с одной стороны, это будут противоречия между силами, стремящимися к институционализации своей деятельности по удовлетворению своих потребностей, и теми, кто сознательно или подсознательно, организованно и не организованно будет тормозить этот процесс. Неверно было бы думать, что интересы и потребности сил как той, так и этой стороны безлично однородны. Речь может идти о совпадении некоторых интересов и потребностей на определенное время. Разная степень осознания этих интересов и потребностей сама по себе также будет играть тормозящую роль как в становлении и развитии новых, так и в процессе разложения существующих социальных институтов. При этом однозначно можно сказать лишь о том, что существующая в обществе система социальных институтов трансформируется, порождая рецидивы аномии [19]. Однако это касается не всех социальных институтов в одинаковой степени: от каких-то проявлений здравоохранения жизнь заставит отказаться полностью; некоторые из них меняются по форме, а определенная часть, очевидно, не испытывает каких-либо серьезных изменений сегодня, чтобы быть отвергнутой наполовину завтра и полностью на послезавтра.

Говоря о социальных институтах, как правило, ограничиваются описанием функций, официально закрепленных за тем или иным институтом. Однако подобный подход к анализу позволяет лишь в определенной мере приблизиться к проблеме, к надводной части айсберга. В итоге выдается только та информация, которая в большей степени выгодна этому институту, в силу чего поддерживается и распространяется им в целях создания определенного 
общественного мнения. На самом деле социальные институты, кроме декларируемых, выполняют еще и неофициальные функции, которые условно называются «теневыми». И здравоохранение здесь не может быть исключением.

В историческом измерении еще совсем недавно близко не было того здравоохранения, которое мы имеем в настоящее время, даже жаловаться на качество «медицинских услуг» было некому и не на кого. Оно появилось и вслед за всевозрастающими потребностями людей прошлых поколений и получило то развитие, которое мы имеем сегодня. Но появилось оно не как отрасль народного хозяйства и не как социальная сфера, а именно как накопленный веками опыт народных целителей. В результате углубления общественного разделения труда появляются отдельные организации, создаваемые в вооруженных силах, на заводах, чтобы оказать больным и раненным медицинскую помощь, так сказать, не отходя от места их полезной деятельности. Позже появляются уже специальные государственные органы, которые формируют систему лечебных организаций и учреждений, создают инфраструктуру, организовывают подготовку профессиональных кадров, начинают развивать медицинскую науку и управлять по отраслевому принципу. Однако отраслевое управление, которое в свое время сыграло безусловно положительную роль в развитии здравоохранении, в новейшую эпоху начинает давать сбои. В советское время это обстоятельство объективно вытеснило здравоохранение в зону господства остаточного принципа, когда появились стратегически важные отрасли, а забота о здоровье человека, забота об общественном здоровье оказалась в ряду «непрофильных активов».

Необходимо отметить, что и в советское время, и в постсоветский период идут активные поиски выхода из этой ситуации, в том числе и в теории управления. Но, как напоминает Т. Парсонс, «..один из важных канонов науки состоит в том, что невозможно исследовать все сразу...» [20, с. 465], очевидно, и на практике невозможно все проблемы решить сразу. Ясно одно, что потребности людей находятся в процессе постоянного развития, возникают потребности в медицинских услугах нового качественного уровня, т.е. система здравоохранения сегодняшнего уровня тоже перестает удовлетворять растущие потребности людей новых поколений. Это касается не только новых поколений пациентов. Проблема гораздо сложнее, чем кажется на первый взгляд. Дело еще в том, что со временем меняется не только структура общественного производства, но и структура болезней населения, меняются медицинские знания и практика врачевания людей в самом широком смысле слова: меняется отношение человека к своему здоровью, к социальному институту здравоохранения.

Институты исторически обусловлены [21, с. 406], и не только они связаны с социально-экономическими условиями в обществе, но и качество здоровья населения связано с типом общественного устройства [22]. Поэтому с те- 
чением времени меняется характер функций социальных институтов, в том числе и здравоохранения. При этом принято считать, что здравоохранение испытанный социальный институт, который только тем и «занят», что аккумулирует в себе и передает следующим поколениям все самое ценное из социального опыта, что накоплено предыдущими поколениями. С этим можно и нужно согласиться. Но, с другой стороны, выполняя свою функцию передачи социального опыта, здравоохранение не ограничивается только тем опытом, который приемлем с точки зрения интересов общества. Как социальный институт, оно накапливает широкий спектр социального опыта, включая и то, что никак не может быть названо общественно необходимым с точки зрения завтрашнего; оно выполняет еще и функцию селективную - отбора, усвоения, переработки этого опыта, исходя из интересов и потребностей конкретных людей. Кроме того, оно выполняет функцию адаптации социального опыта, накопленного предыдущими поколениями, в новых условиях. Такие привычки, как злоупотребление алкоголем, курение, низкий уровень физической культуры, безнравственность, оказание услуг по связям, присущие многим представителям других институций, не чужды и работникам здравоохранения. Особенно это заметно в условиях сельской социально-территориальной общности, где медицинское учреждение, персонал, занятый там, органически входит в социальную структуру общности.

На протяжении всей истории своего существования здравоохранение как социальный институт функционирует в тесной связи с другими социальными институтами, испытывая разной силы «давление» со стороны разных институтов. Представляют интерес в этой связи отношения между здравоохранением и семьей, государством, образованием, религией, которые в разные исторические периоды развития нашего общества имели свои специфические особенности. Исторический опыт показывает, что это взаимодействие может и способствовать развитию, и тормозить развитие здравоохранения. Задача с таким количеством неизвестных, полное решение которой в принципе не под силу в существующих условиях. Но стремиться к тому, чтобы существенно уменьшить количество находящихся на этом пути барьеров и поднять уровень взаимопонимания и взаимодействия между названными выше подсистемами одной единой системы, называемой населением, можно и нужно. Во всяком случае социально-демографические исследования, если их проводить на соответствующем уровне, способны поставлять научные данные, своевременное использование которых поможет преодолеть существующие противоречия меньшими потерями. А практика все с большей настойчивостью показывает, что переход от отраслевой к бесшовной системе взаимодействия социальных институтов является базовым условием перехода общества к инновационному этапу своего развития. 


\section{Список литературы}

1. Козлов Ю.М. Административное право: учеб. - М.: Юристь, 1999. $320 \mathrm{c}$.

2. Баглай М.В., Габричидзе Б.Н. Конституционное право Российской Федерации: учеб. - М.: ИНФРА М-КОДЕКС, 1996. - 512 с.

3. Решетников А.В., Шамшурина Н.Г., Шамшурин В.И. Экономика и управление в здравоохранении: учеб. и практ. для вузов. - М.: Юрайт, 2019. $328 \mathrm{c}$.

4. Журавлева И.В. Отношение к здоровью индивида и общества / Ин-т социологии РАН. - М.: Наука, 2006. -238 с.

5. Вицелярова К.Н., Басанова К.Л. Здравоохранение как элемент социальной сферы // Концепт: [электрон. журн.]. - 2015. - Спецвыпуск № 13. URL: http://e-koncept.ru/2015/75193.htm (дата обращения: 10.09.2019).

6. Богма К.А. Особенности государственной политики в сфере здравоохранения // Здравоохранение Российской Федерации. - 2016. - № 60 (3). C. 162-167. DOI: 10.18821/0044-197X-2016-60-3-162-167

7. Чудинова И.Э. Здравоохранение в изменяющемся обществе: автореф. дис. ... канд. социол. наук: 14.00.52. - Волгоград, 2003. - 23 с.

8. Большой толковый социологический словарь (Collins): пер.с англ. М.: Вече, АСТ, 2001. - С.248.

9. Насибуллин Р.Т., Бикметов Е.Ю., Сизоненко 3.Л. Социология: учеб. пособие. - Уфа: Изд-во УГАТУ, 2006. - С. 285-299.

10. Мертон Р. Явные и латентные функции // Американская социологическая мысль / под ред. В.И. Добренькова. - М.: Изд-во МГУ,1994. - С. 379-448.

11. Андреев Ю.П., Коржевская Н.М., Костина Н.Б. Социальные институты: содержание, функции, структура. - Свердловск: Изд-во Урал. ун-та, 1989. $-83 \mathrm{c}$.

12. Парсонс Т. Функциональная теория изменения // Американская социологическая мысль / под ред. В.И. Добренькова. - М.: Изд-во МГУ, 1994. C. 466-467.

13. Парсонс Т. О социальных системах / под ред. В.Ф. Чеснаковой и С.А. Белановского. - М.: Академический Проект, 2002. -433 с.

14. Эрцлиш К. Болезнь и здоровье как предмет социологии // Социология и социальная антропология. - 1999. - Т. II. - С. 191-198

15. Сорокин П.А. Главные тенденции нашего времени. - М., 2007. -416 c.

16. Добреньков В.И., Кравченко А.И. Социология: учеб. - М.: ИНФРА-М, 2001. $-624 \mathrm{c}$.

17. Богма К.А. Краудсорсинг в системе российского здравоохранения // Государственное и муниципальное управление. Ученые записки СКГС. 2017. - № 3. - C. 192-196. 
18. Социология: учеб. пособие / А.Н. Елсуков, Е.М. Бабосов, А.Н. Данилов [и др.]. - Минск: ТетраСистемс, 2014. -450 с.

19. Дюркгейм Э. Самоубийство: Социологический этюд / пер. с фр. под ред. В.А. Базарова. - М.: Мысль, 1994. - 399 с.

20. Парсонс Т. Система координат действий и общая теория систем действия: культура, личность и место социальных систем // Американская социологическая мысль. - М.: Изд-во МГУ, 1994. - С. 462-478.

21. Маркс К. П.В. Анненкову, 28 декабря 1846 г. // Маркс К., Энгельс Ф. Соч. - Изд. 2-е. - Т. 27. - С. 402-403.

22. Баранов А.А. О социальной парадигме здоровья // Медицина и право. 2001. - Вып. 1. - С. 46-48.

\section{References}

1. Kozlov Iu.M. Administrativnoe parvo [Administrative law]. Moscow, Iurist", 1999, $320 \mathrm{p}$.

2. Baglai M.V., Gabrichidze B.N. Konstitutsionnoe pravo Rossiiskoi Federatsii [Constitutional law of the Russian Federation]. Moscow, INFRA MKODEKS, 1996, $512 \mathrm{p}$.

3. Reshetnikov A.V., Shamshurina N.G., Shamshurin V.I. Ekonomika i upravlenie $\mathrm{v}$ zdravookhranenii [Economics and health management]. Moscow, Iurait, 2019, $328 \mathrm{p}$.

4. Zhuravleva I.V. Otnoshenie k zdorov'iu individa i obshchestva [Attitude to the health of the individual and society]. Institute of Sociology RAS, Moscow, Nauka, 2006, 238 p.

5. Vitseliarova K.N., Basanova K.L. Zdravookhranenie kak element sotsial'noi sfery [Health care as an element of the social sphere]. Kontsept, 2015, no. 13, available at: http://e-koncept.ru/2015/75193.htm (accessed 10 September 2019).

6. Bogma K.A. Osobennosti gosudarstvennoi politiki v sfere zdravookhraneniia [The characteristics of public policy in health care]. Zdravookhranenie Rossiiskoi Federatsii, 2016, no. 60(3), pp. 162-167. DOI: 10.18821/0044-197X-2016-60-3-162-167.

7. Chudinova I.E. Zdravookhranenie $\mathrm{v}$ izmeniaiushchemsia obshchestve [Health care in changing society]. Abstract of Ph.D. thesis. Volgograd, 2003, 23 p.

8. Jary D., Jary J. Collins dictionary of sociology (Russ. ed.: Bol'shoi tolkovyi sotsiologicheskii slovar' (Collins). (A-O). Moscow, Veche, AST, vol. 1, 2001, 248 p.).

9. Nasibullin R.T., Bikmetov E.Iu., Sizonenko Z.L. Sotsiologiia [Sociology]. Ed. R.T. Nasibullin, Ufa, USATU, 2006, pp. 285-299. 
10. Merton R. Iavnye i latentnye funktsii [Obvious and latent functions]. Amerikanskaia sotsiologicheskaia mysl'. Ed. V.I. Dobren'kov. Moscow, MSU, 1994, pp. 379-448.

11. Andreev Iu.P., Korzhevskaia N.M., Kostina N.B. Sotsial'nye instituty: soderzhanie, funktsii, struktura [Social institutes: Content, functions, structure]. Sverdlovsk, Ural Federal University, 1989, 83 p.

12. Parsons T. Functional fit theory (Russ.ed.: Parsons T. Funktsional'naia teoriia izmeneniia. Amerikanskaia sotsiologicheskaia mysl'. Ed. V.I. Dobren'kov. Moscow, MSU, 1994, pp. 466-467).

13. Parsons T. The social system (Russ. ed.: Parsons T. O sotsial'nykh sistemakh. Ed. V.F. Chesnakova, S.A. Belanovskii. Moscow, Akademicheskii Proekt, 2002, 433 p.).

14. Ertslish K. Bolezn' i zdorov'e kak predmet sotsiologii [Disease and health as a subject of sociology]. Sotsiologiia i sotsial'naia antropologiia, 1999, vol. II, pp. 19-198.

15. Sorokin P.A. Glavnye tendentsii nashego vremeni [The main trends of our time]. Moscow, 2007, $416 \mathrm{p}$.

16. Dobren'kov V.I., Kravchenko A.I. Sotsiologiia [Sociology]. Moscow, INFRA-M, 2001, $624 \mathrm{p}$.

17. Bogma K.A. Kraudsorsing $\mathrm{v}$ sisteme Rossiiskogo zdravookhraneniia [Crowdsourcing in the Russian healthcare system]. Gosudarstvennoe $i$ munitsipal'noe upravlenie. Uchenye zapiski SKGS, 2017, no. 3, pp. 192-196.

18. Elsukov A.N., Babosov E.M., Danilov A.N. [et al.]. Sotsiologiia [Sociology]. Ed. A.N. Elsukov, Minsk, TetraSistems, 2014, 450p.

19. Diurkheim D.E. Le suicide. Étude de sociologie (Russ.ed.: Diurkgeim E. Samoubiistvo: Sotsiologicheskii etiud. Ed. V.A. Bazarov. Moscow, Mysl', 1994, 399 p.).

20. Parsons T. The action frame of reference and the general theory of action systems: Culture, personality and the place of social systems (Russ. ed.: Parsons T. Sistema koordinat deistvii i obshchaia teoriia sistem deistviia: kul'tura, lichnost' i mesto sotsial'nykh system. Amerikanskaia sotsiologicheskaia mysl', Moscow, 1994, pp. 462-478.).

21. Marx K. Letter from Marx to Pavel Vasilyevich Annenkov (Russ. ed.: Marks K. P.V. Annenkovu, 28 dekabria 1846 g. Marks K., Engel's F. Sochineniia. 2nd ed., vol. 27, pp. 402-403).

22. Baranov A.A. O sotsial'noi paradigme zdorov'ia [On social paradigm of health]. Meditsina i pravo, 2001, no. 1, pp. 46-48.

Оригинальность $76 \%$

Получено 03.10.2019 Принято 03.11.2019 Опубликовано 15.01.2020 


\section{R.T. Nasibullin}

\section{HEALTHCARE AS A SOCIAL INSTITUTION}

Throughout our lives, each of us, following the example of our parents, friends, colleagues, turns to doctors or traditional medicine when a health problem occurs. So, each person, including researchers, has an idea about what health care is: some consider it as a branch of the national economy, others as a system of state bodies involved in providing the medical services to the population, etc. The author of the article characterizes healthcare as a social institution. From this point of view, it is counterproductive to consider healthcare as a branch of the national economy both from the standpoint of science and practical expediency. A full-fledged implementation of the "Health" national project in Russia is possible only if those entities that combine the forces of nature and human spirit, such as Gazprom, Rosneft, etc., begin to make contributions in the national healthcare system as full participants in common initiative, the main purpose of which is not to transform population's potencies into money at the cost of its health, but rather to create such conditions and life quality of people when every child could receive a decent education, proper professional training followed by a decent form of their abilities development and manifestation, to perceive one's physical and mental health as a supreme value.

Keywords: healthcare, social institution, functions, dysfunctions, roles, norms.

Ravil T. Nasibullin - Doctor of Sociology, Professor, Head of the Department of Sociology and Social Technology, Ufa State Aviation Technical University, e-mail: nasibullin@inbox.ru.

Received 03.10.2019 Accepted 03.11.2019 Published 15.01.2020 